\title{
Implementasi Kelas Ibu Hamil \\ (Penyuluhan Perawatan Payudara Masa Kehamilan dan Menyusui di Puskesmas I Denpasar Utara)
}

\author{
Ni Made Ari Febriyanti", Ni Ketut Ayu Sugiartini \\ Politeknik Kesehatan Kartini Bali \\ * Corresponding Author. Email: arifebri89@gmail.com
}

\begin{abstract}
This community service aims to provide education to pregnant women in the second and third trimesters about the benefits of breast care during pregnancy and breastfeeding. The method used in this service is to provide online counseling about breast care during pregnancy and breastfeeding during class for pregnant women. Participants in this service program are pregnant women in the second and third trimesters who take part in the pregnant women class program at Puskesmas I, North Denpasar. After being given counseling, there was an increase in knowledge of pregnant women about breast care during pregnancy and breastfeeding.
\end{abstract}

\begin{abstract}
Abstrak: Pengabdian ini bertujuan untuk memberikan edukasi kepada ibu hamil trimester II dan III mengenai manfaat perawatan payudara masa hamil dan menyusui. Metode yang dilakukan dalam pengabdian ini yaitu dengan memberikan penyuluhan tentang perawatan payudara masa hamil dan menyusui secara daring (online) pada saat kelas ibu hamil. Peserta dalam program pengabdian ini adalah ibu-ibu hamil trimester II dan III yang mengikuti program kelas ibu hamil di Puskesmas I Denpasar Utara. Setelah diberikan penyuluhan, terjadi peningkatan pengetahuan ibu-ibu hamil tentang perawatan payudara masa hamil dan menyusui.
\end{abstract}

Article History:

Received: 20-09-2021

Reviewed: 12-10-2021

Accepted: 22-10-2021

Published: 13-11-2021

Key Words:

Counseling, Breast

Care, Expectant

Mother.

Sejarah Artikel:

Diterima: 20-09-2021

Direview: $12-10-2021$

Disetujui: 22-10-2021

Diterbitkan: 13-11-2021

\section{Kata Kunci:}

Penyuluhan, Perawatan

Payudara, Ibu Hamil.

How to Cite: Febriyanti, N., \& Sugiartini, N. (2021). Implementasi Kelas Ibu Hamil (Penyuluhan Perawatan Payudara Masa Kehamilan dan Menyusui di Puskesmas I Denpasar Utara). Jurnal Pengabdian UNDIKMA, 2(2), 288-292. doi:https://doi.org/10.33394/jpu.v2i2.4305

https://doi.org/10.33394/jpu.v2i2.4305

This is an open-access article under the CC-BY-SA License.

\section{Pendahuluan}

Pemberian Air Susu Ibu (ASI) secara ekslusif berperan sangat besar guna menurunkan angka kematian bayi dan prevalensi gizi kurang pada anak balita. WHO pada tahun 2003 melaporkan bahwa 60\% kematian balita langsung maupun tidak langsung disebabkan oleh kurang gizi dan 2/3 dari kematian tersebut, disebabkan oleh karena praktik pemberian makanan yang kurang tepat pada bayi dan anak (Depkes RI, 2009).

Cakupan ASI eksklusif di berbagai negara bervariasi. Berdasarkan survei Center for Disease Control and Prevention (CDC) tahun 2014 di Amerika menunjukkan bahwa bayi yang mendapatkan ASI eksklusif sampai umur tiga bulan sebesar 40,7\% dan bayi yang mendapatkan ASI eksklusif hingga usia enam bulan sebesar 18,8\%. Berdasarkan data tersebut dapat dilihat bahwa pemberian ASI menurun seiring dengan bertambahnya usia, padahal banyak sekali manfaat didalam pemberian ASI secara eksklusif. Secara nasional, di Indonesia cakupan bayi mendapat ASI eksklusif tahun 2019 yaitu sebesar 67,74\%, sedangkan di Bali cakupan pemberian ASI eksklusif yaitu sebesar 56,95\% (Kemenkes, 2020) dan Kota Denpasar memiliki pencapaian asi eksklusif terendah yaitu sebesar $60 \%$ dibandingkan dengan kabupaten yang lainnya (Dinkes Prov Bali, 2019). 
Banyak faktor yang mempengaruhi angka kejadian ASI eksklusif diantaranya adalah pengetahuan, sikap, ketersediaan fasilitas dan dukungan keluarga (Septiani dkk, 2017). Pengetahuan berhubungan erat dengan perilaku ibu. Dalam hal ini pada ibu hamil sebagai persiapan menyusui dan ibu nifas yang menyusui bayinya. Saat seorang ibu mengetahui tentang manfaat ASI dan tatalaksana pendukung agar ASI eksklusif terpenuhi, maka ibu tersebut akan melakukannya.

Perawatan payudara adalah salah satu upaya yang penting yang harus diperhatikan dalam keberhasilan pemberian ASI ekslusif. Hal ini karena payudara satu-satunya penghasil ASI yang merupakan makanan bayi baru lahir sehingga dilakukan sedini mungkin. Tetapi pada kenyataannya banyak ibu hamil mengabaikan perawatan payudara. Ini dikarenakan ibu malas atau sesungguhnya ibu belum mengetahui manfaatnya. Pengetahuan dan sikap ibu hamil terhadap perawatan payudara sangat menunjang ibu setelah bersalin, sehingga dapat memberikan ASI eksklusif pada bayi. (Darsina, 2013). Menurut Kumalasari (2015) Perawatan payudara sendiri bertujuan untuk (i) Memelihara kebersihan payudara, (ii) Melenturkan puting susu (iii) Mengurangi risiko lecet saat menyusui (iv) Merangsang produksi ASI (v) Mencegah penyumbatan pada payudara.

Perawatan payudara diberikan pada saat melakukan pemeriksaan antenatal care atau pada saat kelas ibu hamil, namun karena pandemic Covid-19 ini, terjadi keterbatasan ibu hamil untuk mendapatkan pelayanan antenatal care dan kelas ibu hamil. Dimana dengan adanya pembatasan kunjungan ibu hamil dan tidak adanya kelas ibu hamil di Puskesmas I Denpasar Utara,berdampak pula pada pelayanan dalam perawatan payudara untuk persiapan menyusui. Berdasarkan hal tersebut diatas maka perlu dilakukan penyuluhan kepada ibu hamil trimester II dan III tentang pentingnya perawatan payudara pada masa hamil dan menyusui sehingga dapat tercapainya pemberian ASI Eksklusif.

\section{Metode Pengabdian}

Pengabdian Kepada Masyarakat di Puskesmas I Denpasar Utara dilakssanakan selama satu hari pada bulan Agustus 2021. Sasaran dalam kegiatan ini adalah ibu hamil trimester II dan III yang mengikuti kelas ibu hamil secara daring (online). Jumlah ibu hamil yang tim pengabdian berikan penyuluhan adalah sebanyak 10 orang. Dalam mencapai tujuan PkM ini tim pengabdian menggunakan metode :

a) Memberikan penyuluhan tentang perawatan payudara masa hamil dan menyusui

b) Memberikan video edukasi tentang perawatan payudara sehingga bisa dilakukan dirumah.

c) Melakukan evaluasi pengetahuan ibu hamil dalam pelaksanaan kegiatan tersebut dengan memberikan google form yang berisi 10 pertanyaan

\section{Hasil Pengabdian dan Pembahasan}

Pengabdian Kepada Masyarakat (PKM) ini dilaksanakan bekerjasama dengan Puskesmas I Denpasar Utara, Kota Denpasar, Provinsi Bali karena pihak Puskesmas rutin menyelenggarakan kelas ibu hamil sebulan sekali dan selama pandemi Covid-19 ini, dilaksanakan melalui media daring (online). Persiapan kegiatan ini adalah meminta ijin untuk memberikan penyuluhan di kelas ibu hamil dan menyiapkan bahan materi penyuluhan. Penyuluhan 1 hari dan berlangsung selama 30 menit dan diikuti dengan antusias oleh peserta, dimana banyak peserta yang bertanya tentang perawatan payudara.

Penyuluhan dilaksanakan dengan memberikan materi tentang perawatan payudara masa hamil dan menyusui dan berupa audio visual, hal ini bertujuan agar ibu hamil dapat 
Jurnal Pengabdian UNDIKMA:

Jurnal Hasil Pengabdian \& Pemberdayaan kepada Masyarakat https://e-journal.undikma.ac.id/index.php/ipu/index

Email: pengabdian@undikma.ac.id
Vol. 2, No. 2 (November 2021)

E-ISSN : 2722-5097

$P g \quad: 288-292$

melakukan perawatan payudara dirumah masing-masing. Berikut adalah link video perawatan payudara:https://drive.google.com/file/d/1xxY-mopEh4BugwqEV4JCbxYnN-05jy-

$\mathrm{U} / \mathrm{view}$ ? usp=drivesdk

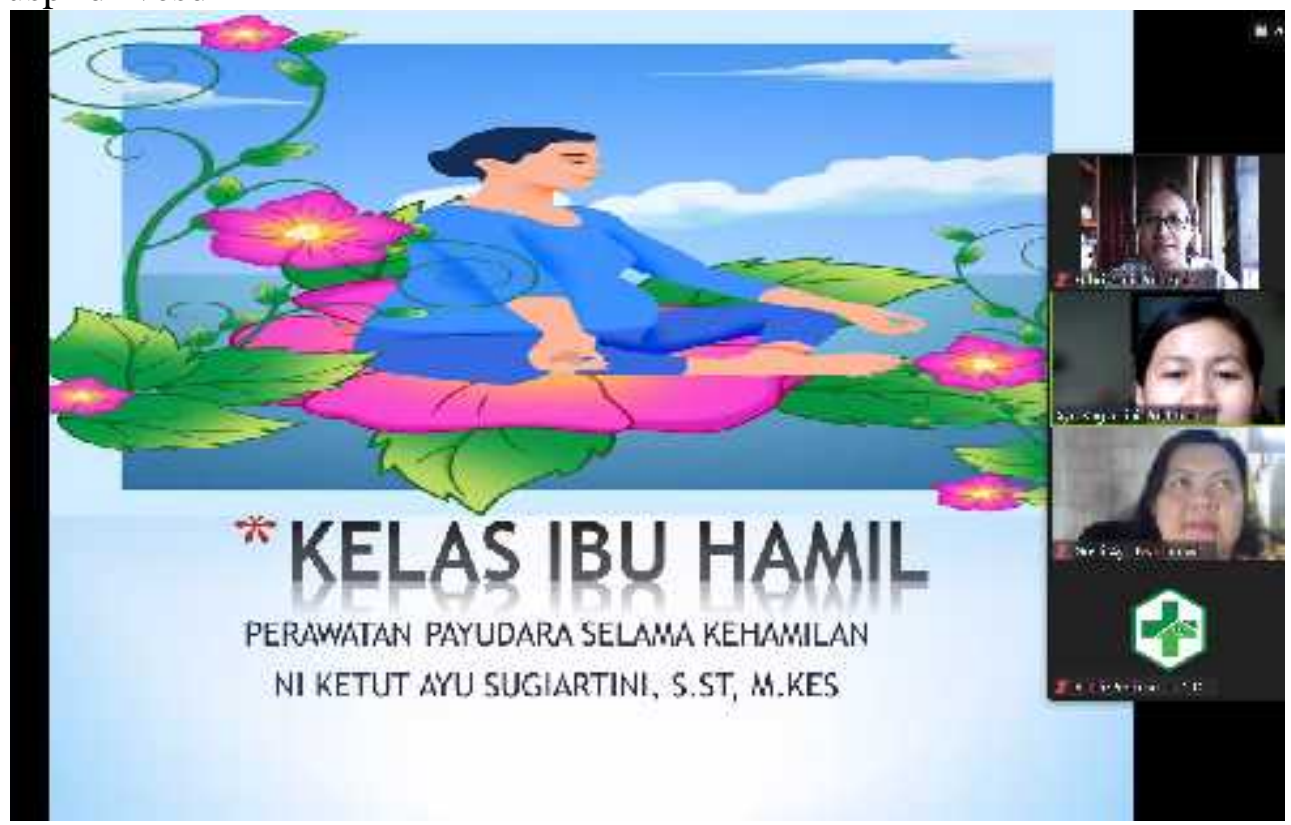

Gambar 1. Penyuluhan Perawatan Payudara Masa Hamil dan Menyusui
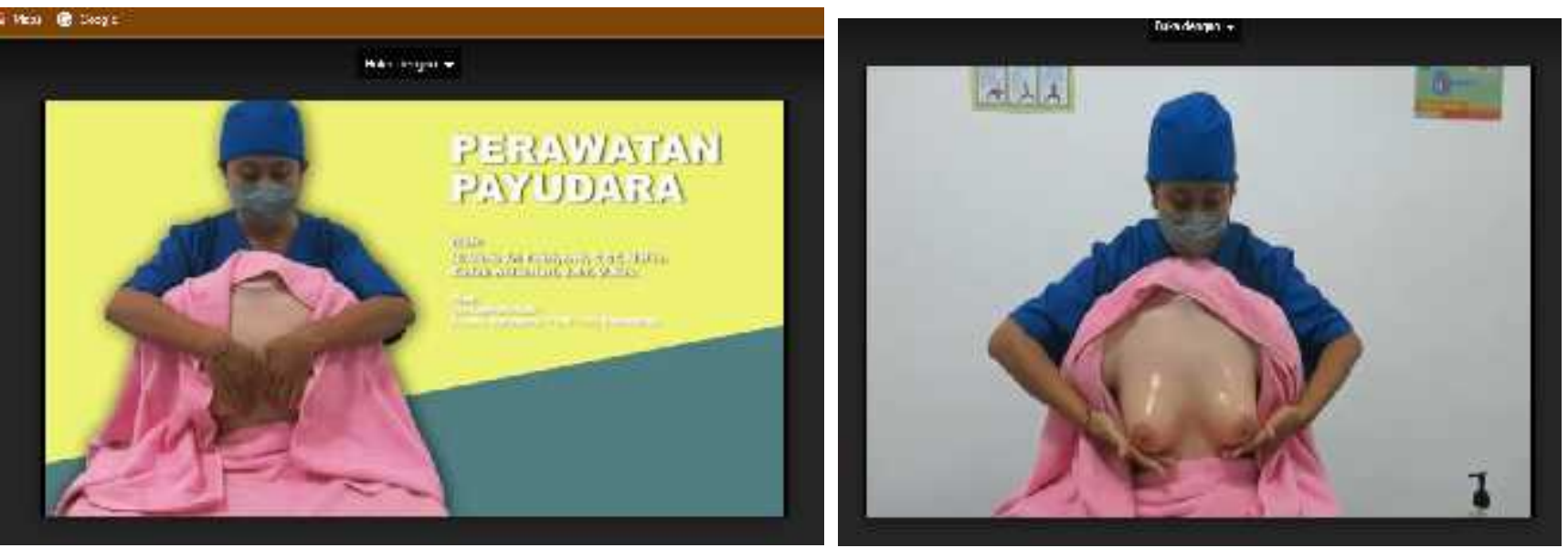

Gambar 2. Media Penyuluhan Perawatan Payudara Masa Hamil dan Menyusui

Pelaksanaan penyuluhan perawatan payudara ini mendapat respon yang sangat baik, terlihat dari antusias ibu hamil dalam mengikuti penyuluhan dan mengisi kuisioner evaluasi kegiatan pengabdian kepada masyarakat ini. Hasil evaluasi pengetahuan ditampilkan pada tabel dibawah ini : 
Email: pengabdian@undikma.ac.id

Tabel 1. Data Pre Test Penyuluhan Peserta

\begin{tabular}{lll}
\hline Pertanyaan & Tepat $(\%)$ & $\begin{array}{l}\text { Tidak Tepat } \\
(\%)\end{array}$ \\
\hline Pertanyaan 1 & 77,2 & 22,8 \\
\hline Pertanyaan 2 & 82,4 & 17,6 \\
\hline Pertanyaan 3 & 61,8 & 83,2 \\
\hline Pertanyaan 4 & 73,5 & 26,5 \\
\hline Pertanyaan 5 & 81,2 & 18,8 \\
\hline Pertanyaan 6 & 77,1 & 22,9 \\
\hline Pertanyaan 7 & 70,6 & 29,4 \\
\hline Pertanyaan 8 & 69,7 & 30,3 \\
\hline Pertanyaan 9 & 60 & 40 \\
\hline Pertanyaan 10 & 72,5 & 27,5 \\
\hline
\end{tabular}

Tabel. 2 Data Post Test Penyuluhan Peserta

\begin{tabular}{lll}
\hline Pertanyaan & Tepat $(\%)$ & $\begin{array}{l}\text { Tidak Tepat } \\
(\%)\end{array}$ \\
\hline Pertanyaan 1 & 92,1 & 7,9 \\
\hline Pertanyaan 2 & 96,2 & 3,8 \\
\hline Pertanyaan 3 & 88,2 & 11,8 \\
\hline Pertanyaan 4 & 96,2 & 3,8 \\
\hline Pertanyaan 5 & 96,2 & 3,8 \\
\hline Pertanyaan 6 & 90,5 & 9,5 \\
\hline Pertanyaan 7 & 97,5 & 2,5 \\
\hline Pertanyaan 8 & 100 & 0 \\
\hline Pertanyaan 9 & 100 & 0 \\
\hline Pertanyaan 10 & 93,6 & 6,4 \\
\hline
\end{tabular}

Dari Tabel di atas dapat dilihat bahwa terjadi peningkatan pengetahuan peserta tentang perawatan payudara. Hal ini sesuai dengan hasil penelitian Idris dan Enggar (2019) bahwa ada pengaruh penyuluhan ASI Eksklusif dengan audio visual terhadap pengetahuan ibu hamil. Pemberian audio visual lebih meningkatkan pemahaman seseorang oleh karena selain pemberian gambar, juga disertai efek suara sehingga indera penglihat dan indera pendengar bekerja secara bersama dan membuat otak bekerja lebih baik untuk penyerapan suatu informasi. Menurut Azwar (2014), pengetahuan seseorang tentang sesuatu hal akan mempengaruhi perilakunya. Peserta dalam pengabdian ini memiliki pengetahuan tentang perawatan payudara dan termotivasi untuk melakukannya. Untuk selanjutnya, setelah pandemic berakhir, akan dilakukan pendampingan perawatan payudara beserta pendampingan menyusui pada peserta pengabdian.

\section{Kesimpulan}

Kesimpulan yang dperoleh dari kegiatan ini adalah (1) Peserta dalam program pengabdian ini sangat antusias mengikuti kegiatan ini dan rutin dilaksanakan, (2) Kegiatan pengabdian kepada masyarakat ini telah membantu ibu-ibu hamil trimester II dan III memperoleh pengetahuan tentang perawatan payudara masa hamil dan menyusui sekaligus dapat menerapkannya dirumah.

\section{Saran}

Saran yang disampaikan berdasarkan hasil kegiatan pengabdian kepada masyarakat ini bagi masyarakat, agar terus meningkatkan pengetahuannya walaupun di masa pandemic dengan mengikuti webinar-webinar. Untuk pihak puskesmas agar terus mengadakan kelas ibu hamil secara online maupun memberikan video edukasi sehingga membuat ibu hamil siap dan termotivasi untuk memberikan ASI eksklusif pada bayinya.

\section{Daftar Pustaka}

Azwar, (2014) Sikap Manusia, Teori dan Pengukurannya. Yogyakarta: Pustaka Belajar. Departemen Kesehatan RI. (2009). Kebijakan Dan Strategi Desentralisasi Bidang Kesehatan. Jakarta 
Dinas Kesehatan Provinsi Bali. (2019). Profil Kesehatan Provinsi Bali Tahun 2019. Denpasar.

Darsina. (2013). Faktor Yang Mempengaruhi Perawatan Payudara Pada Ibu Hamil Trimester III di Puskesmas Meureubo. Universitas Teuku Umar Meulaboh Aceh Barat.

Idris dan Enggar (2019). Pengaruh Penyuluhan Menggunakan Audio Visual tentang ASI Eksklusif terhadap Pengetahuan dan Sikap Ibu Hamil di Puskesmas Singgani Kota Palu. Jurnal Bidan Cerdas Vol. 1 No.2

Kementerian Kesehatan RI. (2020). Profil Kesehatan Indonesia Tahun 2019. Jakarta: Kementerian Kesehatan RI

Kumalasari, Intan. (2015). Panduan Praktek Laboratorium dan Klinik Perawatan Antenatal, Intranatal, Post natal, Bayi Baru Lahir dan Kontrasepsi. Jakarta: Salemba Medika.

Septiani, Hanulan., Budi, Artha., Karbito. (2017). Faktor-faktor yang Berhubungan dengan Pemberian ASI Eksklusif Oleh Ibu Menyusui yang Bekerja Sebagai Tenaga Kesehatan. Aisyah Jurnal Ilmu Kesehatan 2 (2012), hal.159-174. 